\title{
N RETABLO DE ÁNIMAS DE POSIBLE ORIGEN VALENCIANO EN VILLARROYA DE LA SIERRA (ZARAGOZA)
}

JESÚS CRIADO MAINAR

Departamento de Historia del Arte. Universidad de Zaragoza jcm@unizar.es

Resumen: El artículo da a conocer el retablo de almas de la iglesia parroquial de la localidad de Villarroya de la Sierra (Zaragoza), un conjunto barroco configurado entre 1672 y 1674 en el que se incluyó una magnífica pintura sobre tabla de cronología anterior (hacia 1520-1527) para la que aquí proponemos un origen valenciano y que ya formaba parte del ajuar litúrgico del templo en 1607, si bien pensamos que pudo llegar al mismo en una fecha anterior.

Palabras clave: Retablos de almas / arte renacentista / iconografía / circulación de obras de arte.

\section{A RETABLO DE ÁNIMAS OF POSSIBLE VALENCIAN ORIGIN IN VILLARROYA DE LA SIERRA (ZARAGOZA)}

Abstract: The article reveals the altarpiece of souls of the parish church of the village of Villarroya de la Sierra (Zaragoza), a Baroque ensemble set between 1672 and 1674 where a magnificent painting was included on the previous chronological table (towards 1520-1527) for which here we propose a Valencian origin and which was already part of the liturgical trousseau of the temple in 1607, although we think that it could reach it at an earlier date.

Key words: Altarpieces of souls / Renaissance art / iconography / circulation of works of art.

En la iglesia parroquial de San Pedro de Villarroya de la Sierra (Comarca de la Comunidad de Calatayud) se custodia un singular retablo barroco que perteneció a la cofradía de las Ánimas del Purgatorio de la localidad con una inscripción en la parte superior de la predela que confirma esta filiación y permite datarlo en $1674 .{ }^{1}$ Al parecer, esta pía asociación se había fundado tan solo dos años antes, en $1672,{ }^{2}$ circunstancia que concuerda con la realización del mueble y la fecha que luce su mamazonería, pero que no puede hacerse extensiva a la pintura sobre tabla que lo preside.

En las visitas pastorales que cursó al templo el obispo de Tarazona fray Diego de Yepes (15991613) en los años 1604 y 1607 ya se menciona la existencia en el mismo de un altar de las Ánimas, que según precisa la segunda estaba dotado de un "retablo de pincel dorado y bien adornado". 3

\footnotetext{
* Fecha de recepción: 15 abril de 2019 / Fecha de aceptación: 11 de diciembre de 2019.

1 ESTE RETABLO / HICIERON Y DORARON LOS COFRADES DE LAS I AÑO 1674 / ANIMAS DEL PVRGATORIO A ESPENSAS DE I DICHOS COFRADES.

El retablo se menciona, aunque sin citar su advocación, en ABBAD RíOS, Francisco, 1957, t. I, p. 273.

2 De acuerdo con los datos aportados por MILLÁN ESTEBAN, Ángel, 1995, p. 56.

3 Archivo Diocesano de Tarazona [A.D.T.], caja 957, n²4, Visita pastoral al arcedianado de Calatayud de 1603-1604, s. f. (ViIlarroya de la Sierra, 27-VI-1604); y A.D.T., caja 958, n 13, Visita pastoral al arcedianado de Calatayud de 1607, s. f. (Villarroya de la Sierra, 10-X-1607).
} 


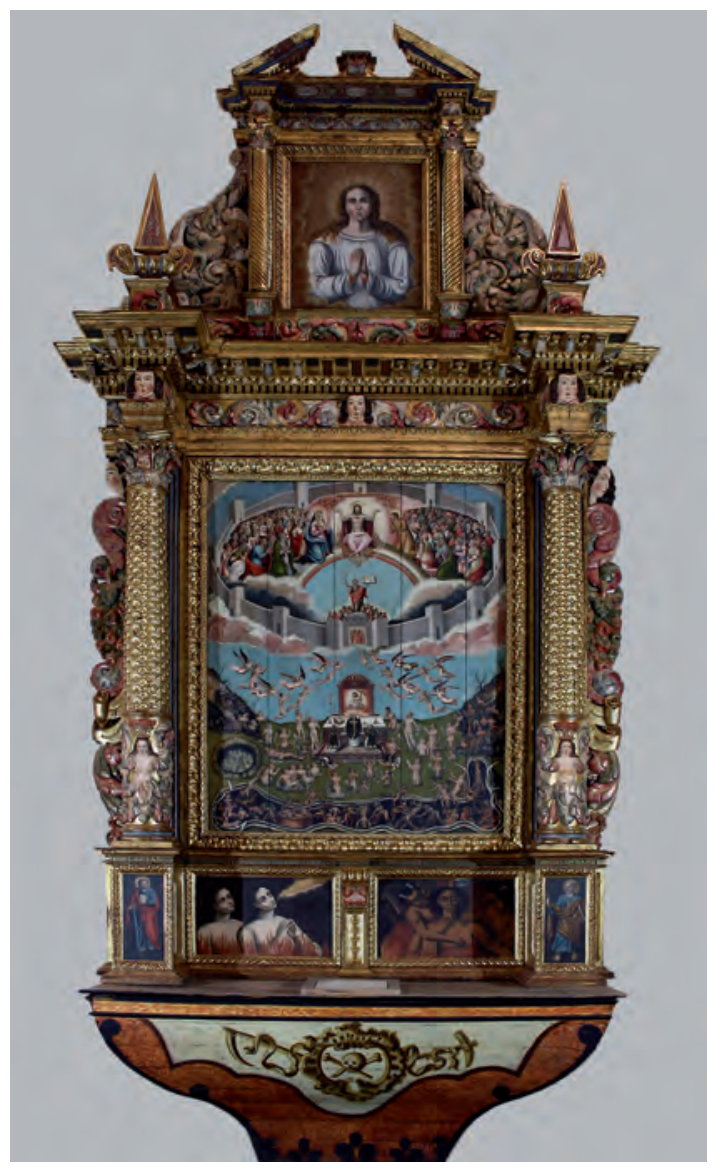

Fig. 1. Villarroya de la Sierra, iglesia parroquial de San Pedro. Retablo de almas, vista general, h. 1672-1674. Foto Isaac González.

Esto significa que la actuación de los cofrades entre 1672 y 1674 debió consistir en la renovación de un retablo preexistente del que se recuperó la pintura sobre tabla titular, que es una creación inequívoca del siglo XVI, para ensamblarla en una arquitectura barroca en la que también se incorporaron dos tablas de nueva factura y pequeño formato en la predela más un lienzo en el ático.

Los datos que acabamos de citar son los únicos conocidos sobre este bello conjunto, recientemente intervenido (2018) en el marco de los planes de restauración de bienes muebles de la Diputación Provincial de Zaragoza. Ello ha permitido restituirle su primitivo esplendor al tiempo que ha facili- tado su estudio y análisis. ${ }^{4}$ No es, pues, posible establecer por el momento las circunstancias en las que la tabla renacentista llegó al templo parroquial, aunque al final de estas páginas formularemos una hipótesis sobre el particular.

\section{Descripción del retablo}

El retablo de las Ánimas del Purgatorio [Fig. 1] de Villarroya de la Sierra ${ }^{5}$ descansa en un banco flanqueado por los pedestales adelantados en los que apean las columnas que delimitan el cuerpo, dividido en dos compartimentos horizontales por una pilastra "ganchuda". En el frente de los pedestales se pintaron los apóstoles San Pedro y San Pablo mientras que en los compartimentos interiores se incluyeron otras tantas evocaciones de los tormentos infringidos en el Purgatorio y el Infierno que justifican la acción pía de la hermandad: en el lado del evangelio Dos almas implorando la oración de los devotos para acortar su estancia en el Purgatorio y en el de la epístola Dos demonios infringiendo tormentos a un alma en el averno; como ya hemos dicho, estas dos tablas se hicieron de forma simultánea al retablo que las alberga.

El cuerpo queda delimitado por columnas corintias anilladas al tercio del imoscapo que lucen en la parte baja canéforas vegetalizadas y en la alta una característica decoración de escamas. Esta forma de resolver las columnas, usada con frecuencia a partir de los años treinta del siglo XVII, cuenta con numerosos precedentes en la comarca bilbilitana entre los que pueden señalarse por su proximidad los soportes -esta vez triples- de la parte interior del cuerpo del retablo de San Gregorio Ostiense de Munébrega. En la parte exterior se adosó un falso guardapolvo con estípites muy del gusto de las décadas centrales del siglo XVII.

Sobre los soportes de la zona noble descansa un entablamento tripartito en el que lo más característico es el friso, que está decorado con motivos vegetales de roleos articulados a partir de una cabecita inserta en la parte central que tiene su correspondencia en las talladas al nivel de las columnas. Esta jugosa arquitectura encuadra la tabla que vamos a estudiar, en la que se ilustró una bella composición con la Misa de San Gregorio y la Jerusalén Celeste.

El conjunto se completa con un ático enmarcado entre semicolumnas de orden compuesto con el

\footnotetext{
${ }^{4}$ La intervención se ha llevado a cabo in situ, sin desmontar el retablo, por lo que no ha sido posible estudiar la parte trasera de la pintura, que no es accesible. Los trabajos de restauración-conservación han estado a cargo de Isaac González Gordo, a quien agradecemos todas las informaciones técnicas de las que nos hemos servido para la elaboración de este texto.

5 Su altura total es de $532,5 \mathrm{~cm}$ y su anchura de $260 \mathrm{~cm}$.
} 
fuste entorchado que reciben un frontón recto abierto. En los laterales, unos aletones muy carnosos que adoptan la forma de amplios tarjetones vegetales ante los que se disponen sendos obeliscos colocados a plomo con las columnas del cuerpo. En el interior de la arquitectura del remate, que es la parte más avanzada de toda la mazonería, se acomoda un lienzo con la Virgen María en actitud intercesora, en clara alusión al papel que le corresponde en el Juicio Final, que también debió ejecutarse a la vez que el mueble barroco.

El conjunto se completa con una mesa de altar de época o, en todo caso, añadida pocos años después, cuyo frente luce una divisa de inequívoco sentido funerario y que ha sido asimismo restaurada con ocasión de los trabajos efectuados en 2018.

\section{La tabla central con la Misa de San Gregorio y la Jerusalén Celeste}

La pintura que preside el retablo de Villarroya de la Sierra [Fig. 2] es un panel de apreciables dimensiones $(168 \times 131 \mathrm{~cm})$ cuyo soporte está constituido por la unión de cinco tablas de anchura regular que se ensamblaron en vertical y que en la actualidad dejan a la vista las uniones al haberse abierto la película pictórica sobre ellas. Desconocemos qué tipo de ensamblaje se usó para ligarlas dado que, como ya se ha indicado, no ha sido posible acceder al reverso.

El artista trabaja la superficie pictórica con todo primor, partiendo siempre de una primera base de color algo más cargada que luego va completando con veladuras de óleo muy sutiles que en ocasiones son casi transparentes y producen bellos efectos cromáticos. Interesa subrayar el tratamiento de los desnudos ilustrados en la mitad inferior, con un cuidado particular en la representación de las formas anatómicas y el modelado volumétrico mediante una atinada contraposición de luces y sombras. Nuestro anónimo pintor efectúa una labor extremadamente meticulosa, casi de miniaturista, prestando gran atención a los detalles que identifican y diferencian a los incontables personajes plasmados en el panel; sobresale, en especial, la original presentación del infierno en la parte inferior, un verdadero alarde de creatividad que denota un encomiable esfuerzo de documentación previa.

El hecho de que se usara la madera como soporte pictórico para una obra de un formato tan consi-

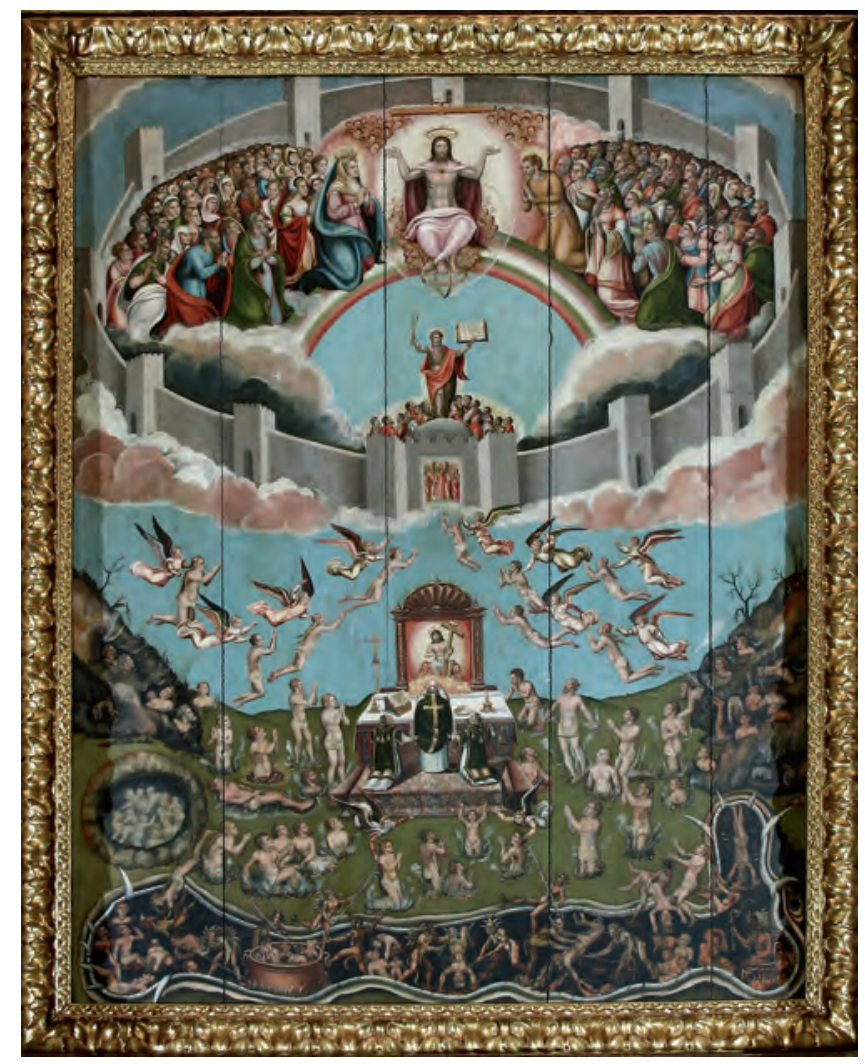

Fig. 2. Villarroya de la Sierra, iglesia parroquial de San Pedro. Retablo de almas, tabla central. Autor desconocido, h. 15201527. Foto Isaac González.

derable descarta una fecha de realización simultánea al retablo, pues el ejemplo más tardío conocido en Aragón de recurso a la pintura sobre tabla para una creación de estas dimensiones es el monumental panel central del retablo de la Misa de San Gregorio (1632-1634) de la iglesia parroquial de Velilla de Jiloca ${ }^{6}$ (Comarca de la Comunidad de Calatayud). Ya hemos expresado, en efecto, que se trata de una pieza de cronología anterior al resto del conjunto, que los cofrades de Villarroya debieron entregar a los artífices para que la ensamblaran en la nueva arquitectura lígnea.

Su iconografía se aparta de la tradición aragonesa de la primera mitad del siglo XVI, que no es tan rica en ejemplos ni en matices como la levantina, bien conocida merced a los estudios de Paulino Rodri-

${ }^{6}$ Obra del pintor bilbilitano Francisco Florén (doc. 1592-1638) que ha estudiado CARRETERO CALVO, Rebeca, 2012, pp. 250256. 
guez. ${ }^{7}$ En los dos primeros casos aragoneses conservados la temática gira en torno al Juicio Final, con la representación de la corte celestial en la parte alta y San Miguel, asociado o no a la psicostasis, en la zona inferior. A esta formulación obedecen, en efecto, tanto la magnífica tabla de la iglesia de la Magdalena de Tarazona ${ }^{8}$ (h. 1536) [Fig. 3] como el retablo conservado en el Museu Nacional d'Art de Catalunya ${ }^{9}$ (h. 1550) [Fig. 4] procedente, al parecer, de la abadía-castillo de Montearagón, junto a Huesca, donde el colectivo de los racioneros había instituido una hermandad de las Almas. ${ }^{10}$

El tercer -y último- ejemplo aragonés a considerar es el retablo de las Almas de Paracuellos de Jiloca (Comarca de la Comunidad de Calatayud), obra del pintor italiano Pietro Morone (doc. 1542$1576, \uparrow 1577)$, que debió hacerlo mientras trabajaba en el retablo mayor (1552-1554/57) del templo parroquial. ${ }^{11}$ Se trata de una máquina articulada en banco y cuerpo de tres calles sobre los que se dispone un ático de compartimento único que alberga una Déesis. El registro central del cuerpo incluye un monumental San Miguel que sostiene la balanza de la psicostasis con el brazo izquierdo al tiempo que Lucifer, vencido a sus pies, intenta manipularla; se trata de la única alusión expresa al Juicio Final recogida en el políptico. En la parte baja de los paneles situados en las calles laterales hay grupos de almas que imploran la salvación -a la izquierda- o son conducidas a la Gloria por ángeles -a la derecha- que otros tantos grupos de santos y justos contemplan desde la parte superior. El compartimento central de la predela está dedicado a la Misa de San Gregorio -un elemento iconográfico ausente de las pinturas de Tarazona y
Montearagón- mientras que el de la izquierda del observador aloja el purgatorio y el de la parte contraria el infierno.

La fuente de la Misa del papa Gregorio Magno (590-604) se encuentra en un prodigio eucarístico de oscuro origen legendario acaecido en la basílica romana de la Santa Cruz en Jerusalén y que, si bien se atribuye a este pontífice, en realidad no tomó forma hasta finales de la Edad Media para asociarse en poco tiempo con las misas gregorianas pro difuntis, cuya génesis es diferente a la del citado milagro. ${ }^{12}$ El éxito que cosecharía a partir del último tercio del siglo XVI obedece en gran medida a la importancia que el Concilio de Trento (1545-1563) concedió al culto a la Sagrada Forma y la presencia real de Cristo en la Eucaristía. Si bien es cierto que su representación independiente en el contexto aragonés remonta al siglo XV, su asociación al Juicio Final es más tardía que en el área levantina y, más allá de su aparición en Paracuellos de Jiloca, no se tornará en frecuente hasta los años de transición entre los siglos XVI y XVII.

Uno de los primeros casos aragoneses en los que la Misa de San Gregorio asume una relevancia equiparable en el marco de un retablo de almas, a la manera de la que tiene en los ejemplos valencianos, es el del magnífico lienzo del Juicio Final con Misa de San Gregorio y Todos Santos (16081611) de la parroquia de San Juan Bautista de Tierga (Comarca del Aranda, Zaragoza), que Rafael Pertús (act. 1585-1646, †1648) pintó a instancias de mosén Millán Blasco ( $† 1616)$, doctor en Teología y vicario de la parroquia de Santiago de Zaragoza, con la intención de colocarla sobre su sepul-

\footnotetext{
7 RODRÍGUEZ BARRAL, Paulino, 2003, pp. 603-648, y 2007, pp. 234-266.

${ }^{8}$ En realidad, una puerta de retablo que luce en el anverso una Inmaculada Concepción y en el reverso el asunto que nos interesa. Su realización se atribuye a Juan Fernández Rodríguez (doc. 1528-1544, †1546) en MORTE GARCíA, Carmen, 1990, pp. 107-112. Las circunstancias exactas de su procedencia se aportan en AINAGA ANDRÉS, Mª Teresa y CRIADO MAINAR, Jesús, 1997, pp. 45-50. Su análisis iconográfico en RODRÍGUEZ BARRAL, Paulino, 2007, pp. 267-268.

${ }^{9} \mathrm{~N}^{\circ}$ inv. 009916-000. El primero en ocuparse de esta obra fue RODRÍGUEZ BARRAL, Paulino, 2007, pp. 268-269, que efectúa un detallado estudio iconográfico de la tabla. Su atribución a Tomás Peliguet (doc. 1537-1579) en MORTE GARCíA, Carmen, 2009, pp. 210-211. Véanse asimismo las puntualizaciones aportadas en VILLACAMPA SANVICENTE, Susana, 2017, pp. 157-158.

10 Documentada, no obstante, tan sólo para fechas bastante posteriores, con motivo de la elaboración de sus ordinaciones en 1699-1716. En ARCO, Ricardo del, 1914, p. 389.

El magnífico retablo mayor de alabastro de la iglesia de la abadía (Museo Diocesano de Huesca), que contrató en 1506 el escultor Gil Morlanes el Viejo, también estaba presidido por una representación del Juicio Final que incluía en la parte baja a San Miguel vencedor de Satanás. Véase, en particular, lo expresado a propósito de la iconografía de la casa central en VILLACAMPA SANVICENTE, Susana, 2000, pp. 198-202.

11 CRIADO MAINAR, Jesús, 2008, pp. 95-96; p. 97, fig. n 53; y pp. 255-257, docs. núms. 3 y 4.

12 RODRÍGUEZ BARRAL, Paulino, 2007, pp. 204-213 y 260-263. Sobre los trentenarios y misas de San Gregorio después del Concilio de Trento véase, en particular, MARTínEZ GIL, Fernando, 1993, pp. 213-221.
} 


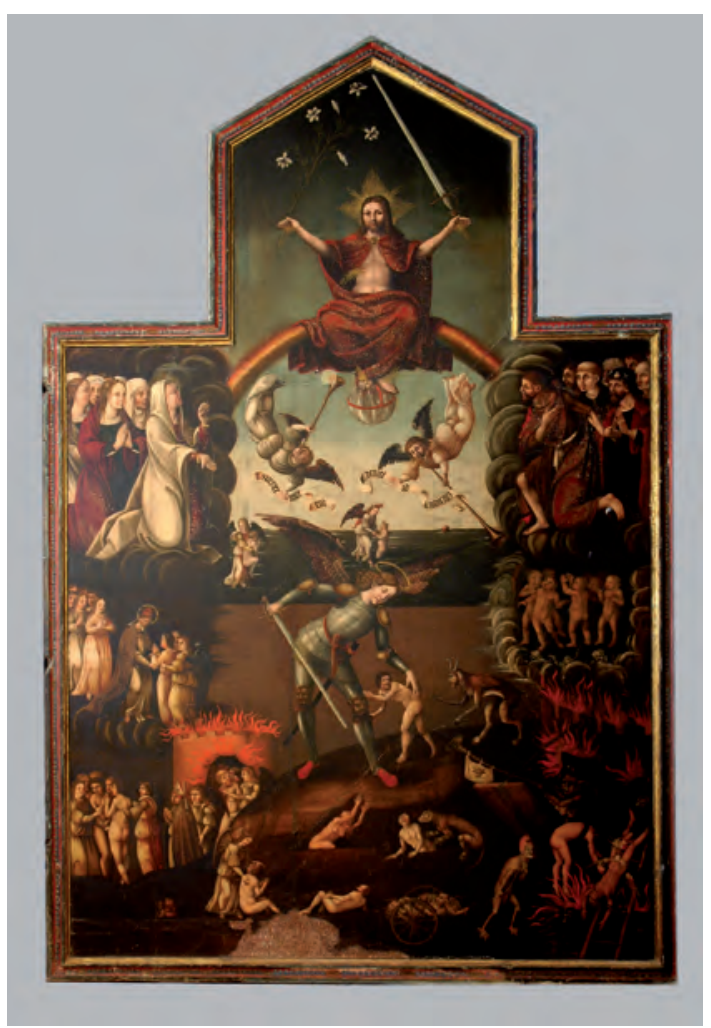

Fig. 3. Tarazona, iglesia parroquial de Santa María Magdalena. Juicio Final. Juan Fernández Rodríguez (atrib.), h. 1536. Foto Rafael Lapuente.

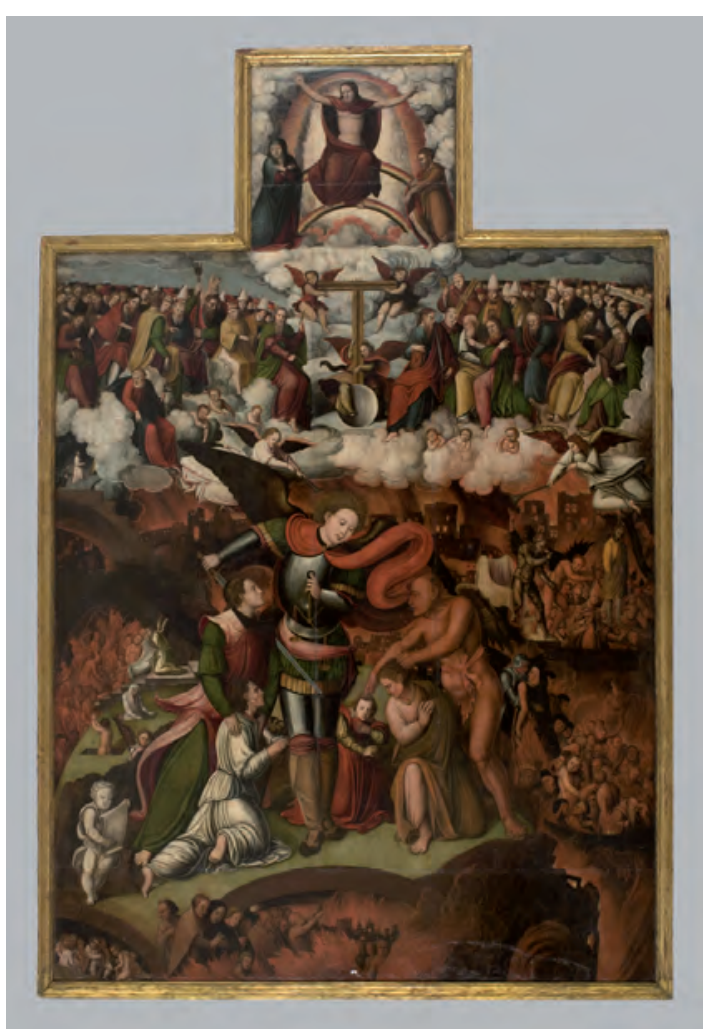

Fig. 4. Barcelona, MNAC. Retablo de almas procedente de la abadía-castillo de Montearagón. Tomás Peliguet (atrib.), h. 1550. Foto MNAC. tura, que debía efectuarse en el suelo, junto a la entrada del templo. ${ }^{13}$ En otras versiones de esos mismos años se le concede un protagonismo aún mayor, como ocurre en los retablos de Morata de Jiloca $^{14}$ (h. 1594-1600) -donde ocupa el compartimento central- y Velilla de Jiloca ${ }^{15}$ (1632-1634) -en el que se ha erigido en argumento único-.

Sin embargo, la tabla de Villarroya de la Sierra es mucho más que una Misa de San Gregorio. Su iconografía se aproxima a la ilustrada -casi con tantas variantes como ejemplos conocidos- en algunos de los más tempranos retablos de almas levan- vantinos, un conjunto de piezas extenso con ejemplares datados entre el último tercio del siglo XV y el tercer cuarto del XVI. Tal y como ha demostrado Paulino Rodríguez, una parte de estos retablos valencianos adopta como argumento central la descripción del Juicio Final ${ }^{16}$ mientras que otros constituyen una evocación atemporal de la Segunda Venida o Parusía de Cristo que se completa con la ilustración de los lugares escatológicos del cielo, el infierno, el purgatorio y el limbo de los niños para proponer a la meditación de los fieles los diferentes destinos a los que se enfrenta el alma humana.

13 Estudiado por CRIADO MAINAR, Jesús, 2012, pp. 271-276.

14 Acompañado del Infierno en el compartimento central de la predela, el Limbo de los niños en la calle del lado del evangelio del cuerpo y el Purgatorio en idéntica ubicación pero a la parte de la epístola. Preside el ático un Cristo de la Parusía. En CRIADO MAINAR, Jesús. 2008, p. 217, fig. n 145.

15 CARRETERO CALVO, Rebeca, 2012, pp. 250-257. En esta oportunidad se omite cualquier referencia a los espacios escatológicos del más allá.

${ }^{16}$ Cuando se incluyen elementos que aluden al mismo de forma explícita, tales como los ángeles que hacen sonar las trompetas, la resurrección de los muertos, el pesaje de las almas o la separación de justos y réprobos. Evidentemente, también se suele representar en ellos los lugares escatológicos. 
Muchos de estos retablos muestran, en efecto, en su parte baja una recreación del infierno, el purgatorio y el limbo de los niños -pero no necesariamente la de todos ellos-, presidida o no por la Misa de San Gregorio. La parte alta incluye una evocación de la Gloria que en ocasiones adopta la forma de un Juicio Final y otras veces la de una Segunda Parusía que tanto en uno como en otro caso pueden contextualizarse dentro de una Jerusalén Celeste, siempre con una de sus doce puertas abierta para posibilitar el ingreso de las almas que ascienden una vez concluida su purificación.

En la zona inferior de nuestra pintura se muestran los tres últimos lugares escatológicos mencionados. Vemos, en primer lugar, un aterrador averno con forma de una oblonga boca de Leviatán en cuyo interior sufren tormento las almas condenadas al fuego eterno. También forman parte del infierno las colinas de los laterales, salpicadas de aberturas por las que caen al abismo las almas réprobas.

Sobre la boca de Leviatán se dispone el purgatorio, un etéreo espacio intermedio poblado por almas en proceso de purificación que emergen del suelo entre fumarolas, en su mayoría en actitud orante; casi todas dirigen su mirada hacia la parte central, adonde se acercan las que están próximas a abandonar este tormento temporal para asistir a la celebración de la Santa Misa que San Gregorio oficia sobre una mesa de altar presidida por un retablo con un Cristo Varón de Dolores que rememora la visión del pontífice. ${ }^{17} \mathrm{~A}$ medida que quedan redimidas, las almas se elevan al tiempo que un grupo de ángeles psicopompos las conducen a la Gloria.

Tampoco falta una descripción del limbo de los niños, concebido como una gruta circular ubicada a la izquierda del observador, en la que se agolpa un grupo de almas infantiles hábilmente desdibujadas por el pintor para recordar que han sido privadas de la contemplación de la majestad divina.

Como ya hemos dicho, en nuestro retablo la Gloria adopta la forma de la Jerusalén Celeste [Fig. 5], una ciudad circular que por efecto de la perspectiva percibimos con forma elíptica y en cuya muralla se distribuyen de manera regular doce torreones con sus correspondientes puertas. La de la parte central, flanqueada por dos torres y cubierta por una cúpula, está abierta para permitir el ingreso de las almas redimidas, conducidas por ángeles y recibidas por acólitos revestidos -uno de los cuales sostiene una cruz procesional- que preceden a una turba de mártires. Todo sucede bajo la atenta supervisión de San Pedro apóstol, en pie sobre la cúpula, que exhibe en sus manos las llaves del cielo y el libro de las almas salvadas al tiempo que se acompaña de un grupo de hombres justos. La solución otorgada a esta zona parece inspirarse el himno gregoriano In paradisum que se recita en el oficio de difuntos:

\section{In paradisum deducant te angeli; \\ in tuo adventu suscipiant te martyres, \\ et perducant te in civitatem sanctam Jerusalem. \\ Chorus angelorum te suscipiat, \\ et cum Lazaro quondam paupere aeternam \\ habeas requiem. ${ }^{18}$}

En el libro de las almas salvadas que porta el primer papa de la Iglesia Romana el pintor anotó dos textos bíblicos. En la página izquierda se lee con toda claridad: Tu es Christus filio Dei vivi. Ma $16^{19}$ que, tal y como precisa la propia inscripción, es una cita extraída del evangelio de San Mateo (cap. 16, vv. 16-17) que proclama la naturaleza divina del Salvador y justifica su Segunda Venida para juzgar a vivos y muertos. Más interés presenta, si cabe, el texto de la página derecha, donde se lee: "Fides sine operibus mortua est. Jaco. 13 Ca. $2 ",{ }^{20}$ tomado de la epístola de Santiago (cap. 2, v. 19) y con el que se alude al papel de la obras pías como contrapunto indispensable de la fe para alcanzar la salvación, una doctrina que está detrás de la gestación del purgatorio en los siglos XII-XIII y que permite comprender el éxito de la labor que desarrollaron las nuevas órdenes mendicantes -en especial, franciscanos, dominicos, carmelitas y agustinos- surgidas por entonces. ${ }^{21}$ Como veremos, la Reforma luterana dio un giro copernicano a esta cuestión que es necesario tener en cuenta para entender los posibles motivos que explican la incorporación de estos textos -en especial, la del segundo- a nuestra pintura.

\footnotetext{
17 SELA DEL POZO COLL, Patricia, 2009, pp. 191-201, espec. 193-194.

18 "Al paraíso te lleven los ángeles / a tu llegada te reciban los mártires / y te introduzcan en la ciudad santa de Jerusalén. / El coro de los ángeles te reciba / y junto con Lázaro, pobre en esta vida, / tengas descanso eterno".

19 Tú eres Cristo, el hijo de Dios vivo.

20 La fe sin obras está muerta.

${ }^{21}$ Nos parece muy sagaz la lectura del marco general que propone LITTLE, Lester K., 1980, pp. 243-267.
} 


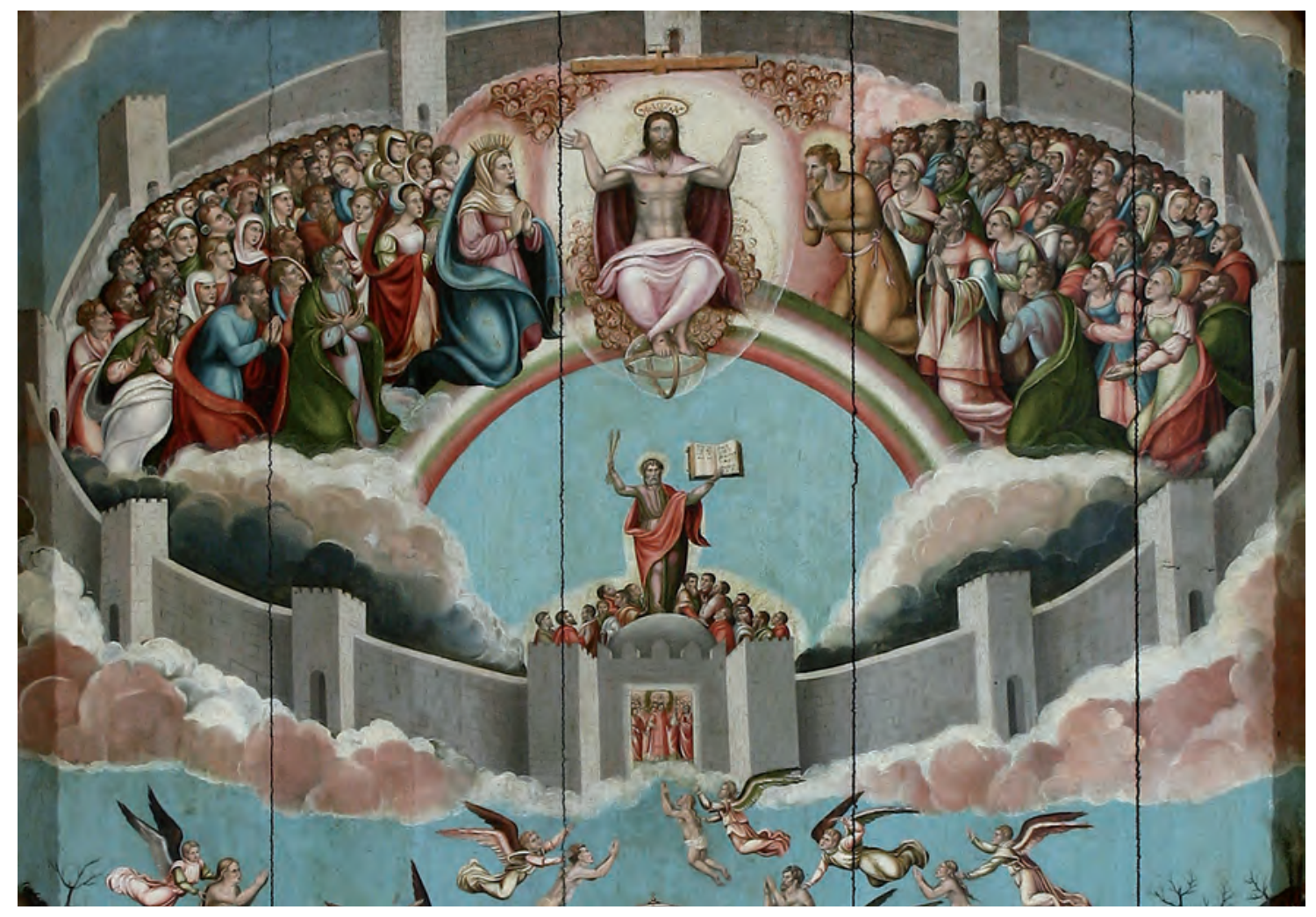

Fig. 5. Villarroya de la Sierra, iglesia parroquial de San Pedro. Retablo de almas, detalle de la tabla central. Autor desconocido, h. 1520-1527. Foto Isaac González.

En el interior de la Ciudad Celestial se despliega una teofanía articulada en torno a un arco iris sobre el que se alza el Cristo de la Segunda Parusía con los brazos abiertos para mostrar las llagas de la Pasión. Antepuesto a la cruz, luce el orbe a los pies $^{22}$ y está rodeado por una mandorla de luz que soporta un coro de ángeles junto a la que se arrodillan en actitud orante la Virgen María y San Juan Bautista para escenificar su condición de intercesores; con ellos forma una Déesis. A sus lados la turba de los justos, hombres y mujeres que ya han alcanzado la salvación entre los que tan solo se reconoce al profeta Moisés, el elegido para transmitir al pueblo de Israel las Tablas de la Ley, situado a la izquierda del Precursor.

Aunque no hemos localizado ningún ejemplo que aporte un modelo exacto para nuestra pintura, el retablo de almas de Catarroja (Valencia) [Fig. 6], destruido en 1936 pero conocido por una fotografía del Archivo Mas de Barcelona, ${ }^{23}$ facilita un referente compositivo $y$, en menor medida, iconográfico, ${ }^{24}$ pues tanto la Misa de San Gregorio entre el Purgatorio y el Infierno como la Déesis inserta en la Jerusalén Celeste recuerdan la solución de Villarroya de la Sierra. ${ }^{25}$

${ }^{22}$ Ceñido por dos anillos perpendiculares que le otorgan el aspecto de una esfera armilar.

${ }^{23}$ Estudiado y reproducido por RODRÍGUEZ BARRAL, Paulino, 2003, p. 636, fig. n² 2; y RODRÍGUEZ BARRAL, Paulino, 2007, p. 356, fig. $n^{\circ} 103$.

${ }^{24}$ La presencia en la parte izquierda del retablo de Catarroja de un ángel trompetero y la inclusión justo debajo de un grupito de almas que resucitan lo convierten en una ilustración del Juicio Final. Estos elementos faltan en Villarroya de la Sierra.

${ }^{25}$ La incorporación en la predela barroca de pinturas dedicadas al Purgatorio y el Infierno también remite al modelo de los retablos de almas valencianos sin que, evidentemente, se pueda establecer una relación directa en atención a su cronología más tardía. Puede verse, por ejemplo, en el retablo que Nicolás Borrás pintó en 1574 para la concatedral de Alicante. En HERNÁNDEZ GUARDIOLA, Lorenzo, 2010, p. 50 y fig. de la p. 51. 


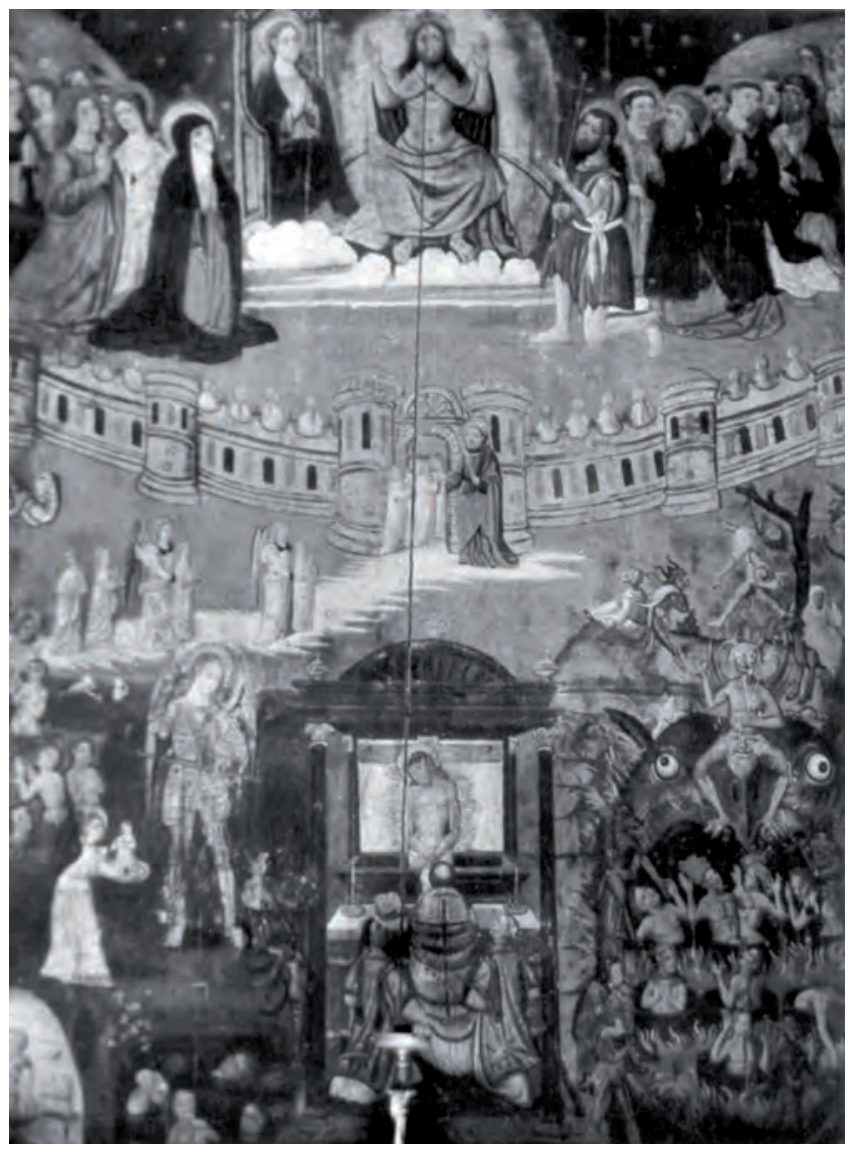

Fig. 6. Catarroja, iglesia parroquial. Retablo de almas (desaparecido), h. 1520. Foto Archivo Mas de Barcelona.

A la vista de todo lo expresado hasta aquí podemos concluir que nuestra pintura es una creación renacentista, probablemente materializada en el segundo cuarto del siglo XVI, lo que otorga pleno sentido a la información que suministran las visitas pastorales de 1604 y 1607 al señalar que para entonces $-y$, sin duda, desde tiempo atrás- ya había un altar de madera pintada con dicha advocación en el templo parroquial.

Este hecho, unido a las diferencias iconográficas que la separan de las otras pinturas aragonesas del mismo asunto de esos años a las que ya hemos hecho alusión, obligan a considerar la posibilidad de que la tabla no se hiciera en Aragón y que, lejos de ello, en realidad tenga un origen levantino.

Pero ¿cuándo y en medio de qué circunstancias llegó a Villarroya de la Sierra? Estas preguntas carecen hoy por hoy de una respuesta segura, pero ello no nos impide reflexionar brevemente en torno a esta cuestión para apuntar alguna idea.

\section{Una hipótesis en torno al primitivo retablo del siglo XVI y la tabla de la Misa de San Gregorio y la Jerusalén Celeste}

Como hemos intentado argumentar, las visitas pastorales cursadas por el prelado jerónimo fray Diego de Yepes en 1604 y 1607 acreditan que en ese momento ya existía en la iglesia parroquial de Villarroya de la Sierra un retablo pictórico dedicado a las Ánimas del que debe proceder el panel que preside el actual mueble barroco. Se da el caso de que los únicos recorridos pastorales efectuados al templo en el siglo XVI de los que nos han llegado los oportunos registros escritos, de 1530 y $1545,{ }^{26}$ no lo mencionan, lo que significa que nuestra tabla debió llegar a su actual destino algo más tarde, en un arco temporal comprendido entre 1545 y 1604.

Estos hechos, unidos a la proximidad iconográfica y compositiva existente entre nuestra pintura y el desaparecido retablo de Almas de Catarroja, aconsejan traer a colación a un hijo ilustre de la localidad, el doctor Andrés Palacios, jurista y servidor de la Monarquía Hispánica. ${ }^{27}$ Fernando II el Católico le encomendó en 1509 la conflictiva tarea de establecer el tribunal de la Inquisición en Nápoles $^{28}$ pero como este intento fracasó, el 6 de junio de 1511 fue destinado al tribunal de Valencia, donde compartió título de inquisidor y responsabilidades con el canónigo bilbilitano Juan Calvo y donde permaneció hasta $1527 .^{29}$ Luis de Páramo, cronista del Santo Oficio, refiere que don Andrés acabó contrayendo matrimonio ${ }^{30} \mathrm{y}$, según Miguel Martínez del Villar, que corrobora este último ex-

26 A.D.T., caja 951, n 1, Visita pastoral al arcedianado de Calatayud de 1530, s. f. (Villarroya de la Sierra, 28-IX-1530); y A.D.T., caja 953, $n^{\circ} 1$, caja 957, n²4, Visita pastoral al arcedianado de Calatayud de 1545 (Villarroya de la Sierra, 14-XI-1545).

27 Queremos agradecer a José Luis Cortés Perruca, Consejero del Centro de Estudios Bilbilitanos, la generosidad de haber llamado nuestra atención sobre este eclesiástico.

${ }^{28}$ ÇVRITA, Geronimo, 1580, lib. VIII, cap. XXXIV, ff. 186v.-187. Citamos por la edición facsimilar de Zaragoza, Institución “Fernando el Católico", 1999. Véase también LEA, Henry Charles, 1908, pp. 56-57; y AMABILE, Luigi, 1892, que se ocupa de la cuestión en las pp. 103-109.

${ }^{29}$ La designación para el tribunal de Valencia en LEA, Henry Charles, 1908, p. 63, nota n 1 . La fecha de finalización de su mandato la ofrece GARCÍA CÁRCEL, Ricardo, 1976, p. 114.

30 PARAMO, Ludovico, 1598, lib. II, tit. 2, cap. 9, p. 189. 


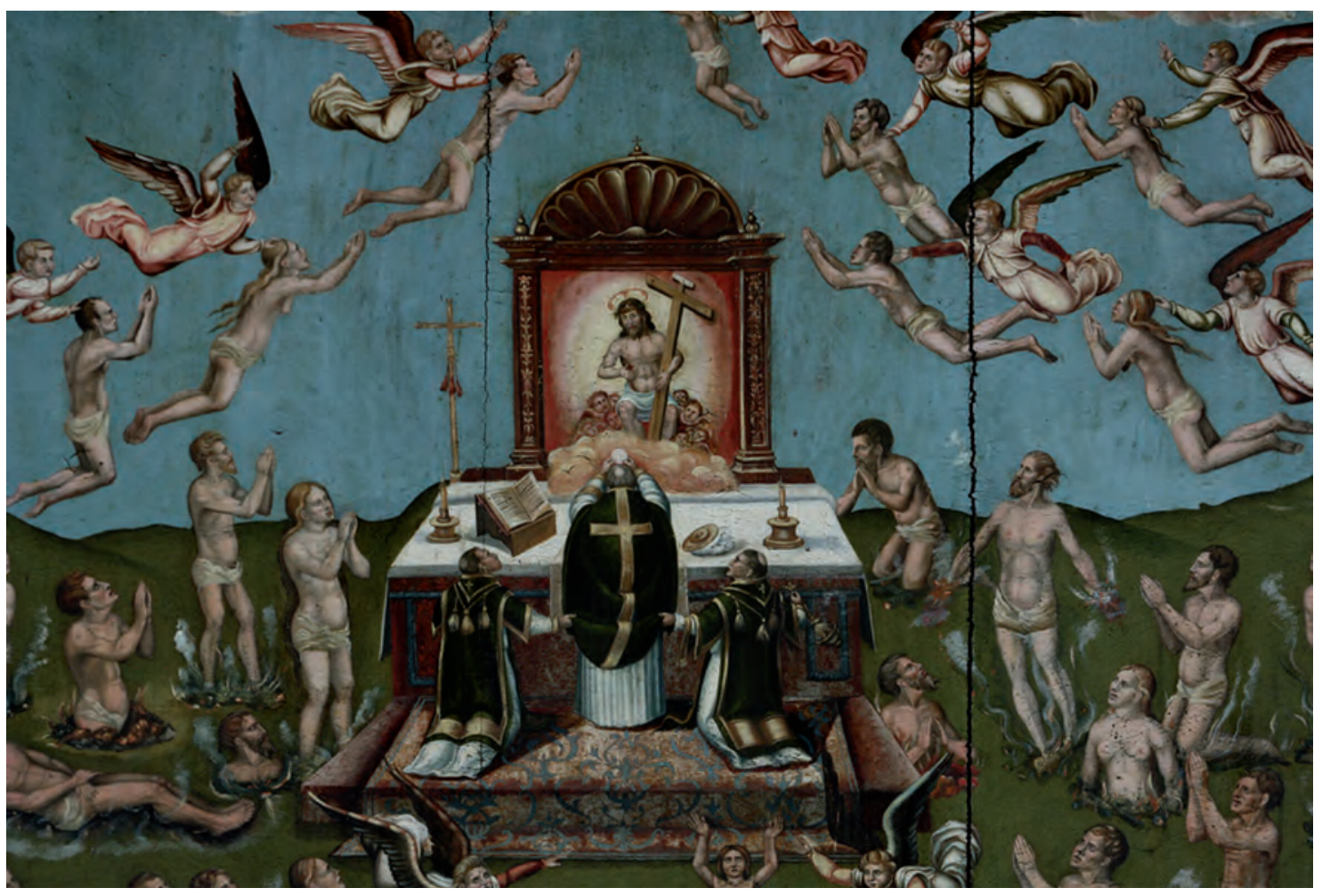

Fig. 7. Villarroya de la Sierra, iglesia parroquial de San Pedro. Retablo de almas, detalle de la tabla central. Autor desconocido, h. 1520-1527. Foto Isaac González.

tremo, después ejerció como asesor del tribunal inquisitorial de Zaragoza. ${ }^{31}$ Estos son los únicos datos que conocemos de este conspicuo personaje que, al parecer no vivió mucho más allá de 1535.

Interesa, pues, a nuestro propósito subrayar que Andrés Palacios ejerció como inquisidor del tribunal de Valencia entre 1511 (en realidad, parece que no se incorporó al mismo hasta 1512) y 1527, momento en que fue relevado, pues queremos proponer la hipótesis de que durante esos años, necesariamente cerca de la última fecha, ${ }^{32}$ pudo hacerse con la pintura que preside el retablo de las Ánimas de su localidad natal.

En este contexto resulta básico recordar que en el libro de las almas salvadas que exhibe San Pedro sobre la puerta principal de la Jerusalén Celeste se transcribió el célebre versículo de la epístola de Santiago en el que se expresa que la fe sin obras está muerta. Frente a este aserto, la Reforma luterana había negado desde el momento de su irrupción en el debate público a finales de la segunda década el papel redentor de las buenas obras, reivindicando la doctrina de la plena justificación por la sola fe. Nuestra pintura se alinea, pues, con la ortodoxia romana, reformulada en 1547 en el marco de la sexta sesión del Concilio de Trento; una postura que se atiene a lo que cabía esperar de un alto funcionario de la Inquisición, cuya primera responsabilidad era velar por la pureza de la fe y perseguir cualquier conato de herejía.

Dado que no parece que la tabla hubiera ingresado en la parroquia de Villarroya de la Sierra en $1545^{33}$ y habida cuenta que el Dr. Palacios falleció

31 MARTínEZ DEL VILLAR, Miguel, 1598, Décima Parte, p. 493. El autor lo presenta también como corregidor de Burgos, un dato que no hemos podido corroborar. Señala que falleció en el Palacio de la Aljafería de Zaragoza sirviendo a la inquisición aragonesa en calidad de asesor "por auerse casado" y que "florecio por los años de 1535".

32 Ya no solo por su contenido iconográfico, sino también por su estilo.

${ }^{33}$ No obstante, a pesar de que la visita pastoral de 1545 no menciona ningún altar en la parroquia bajo título de las Almas, no hay que descartar la posibilidad de que la pintura ya estuviera en el templo y que solo años después se tomara la decisión de que presidiera un altar. 
unos años antes (en torno a 1535), cabe presumir que la entregaran sus deudos en cumplimiento de una disposición testamentaria del inquisidor $y$ que, tiempo después, al calor del nuevo ambiente religioso de la Contrarreforma, se ensamblara en un retablo de Almas.

Lo que proponemos no es más que una hipótesis hoy por hoy indemostrable, pero que tiene la virtud de aportar un contexto plausible a la sorprendente presencia en esta parroquia de la Diócesis de Tarazona, en el occidente de la para entonces ya extinta Corona de Aragón, de una pintura que encaja mucho mejor en los usos y costumbres iconográficos levantinos en torno al tránsito al más allá que en los aragoneses, menos ricos y sofisticados que aquellos en las primeras décadas del siglo XVI. Un marco cronológico que, como hemos intentado justificar, es el que más conviene a una bella pintura sobre tabla que la suciedad, la oxidación de los barnices que la protegían y su incorporación en fecha tardía a un retablo de finales del siglo XVII han ayudado a ocultar, pero a la que una reciente limpieza ha restituido todo su esplendor.

\section{Bibliografía}

ABBAD RíOS, Francisco. Catálogo monumental de España. Zaragoza. Madrid: Instituto "Diego Velázquez" del C.S.I.C., 1957, 2 vols.

AINAGA ANDRÉS, Ma Teresa y CRIADO MAINAR, Jesús. La iglesia parroquial de Santa María Magdalena de Tarazona. Estudio histórico-artistico. Tarazona: Asociación de Vecinos El Cinto, 1997.

AMABILE, Luigi. I/ Santo Officio dell'Inquisizione a Napoli, Città di Castello, 1892.

ARCO, Ricardo del. "El monasterio de Montearagón (continuación)". Linajes de Aragón, V, 21, Huesca, 1914, pp. 377-396.

CARRETERO CALVO, Rebeca. "Retablo de la Misa de San Gregorio". En CALVO RUATA, José Ignacio (coord.), Joyas de un Patrimonio IV. Estudios. Zaragoza: Diputación de Zaragoza, 2012, pp. 250-256.

CRIADO MAINAR, Jesús. El Renacimiento en la Comarca de la Comunidad de Calatayud. Pintura y escultura. Calatayud: Centro de Estudios Bilbilitanos y Comarca Comunidad de Calatayud, 2008.

CRIADO MAINAR, Jesús. "Juicio Final, Misa de San Gregorio y Todos los Santos". En CALVO RUATA, José Ignacio (coord.), 2012, pp. 271-276.

ÇVRITA, Geronimo. Los cinco libros postreros de la Historia del Rey don Hernando el Catholico. De las empresas, y ligas de Italia. Zaragoza: Domingo de Portonariis, 1580.
GARCÍA CÁRCEL, Ricardo. Orígenes de la Inquisición española: el Tribunal de Valencia, 1478-1530. Barcelona: Península, 1976.

HERNÁNDEZ GUARDIOLA, Lorenzo. Nicolás Borrás (1530-1610). Un pintor valenciano del Renacimiento. Valencia: Generalitat Valenciana, Corts Valencianes y Museu de Belles Arts de València, 2010.

LEA, Henry Charles. The Inquisition in the Spanish Dependencies: Sicily, Naples, Sardinia, Milan. Nueva York: The McMillan Company, 1908.

LITTLE, Lester K. Pobreza voluntaria y economía de beneficio en la Europa medieval, Madrid: Taurus, 1980.

MARTÍNEZ DEL VILLAR, Miguel. Tratado del patronado, antigvedades, gouierno, y Varones illustres de la Ciudad, y Comunidad de Calatayud, y su Arcedianado. Zaragoza: Lorenzo de Robles, 1598.

MARTíNEZ GIL, Fernando. Muerte y sociedad en la España de los Austrias. Madrid: Siglo XXI, 1993.

MILLÁN ESTEBAN, Ángel. El santuario de la Virgen de la Sierra: encuentro con un milenio de historia. Zaragoza: Diputación de Zaragoza, 1995.

MORTE GARCÍA, Carmen. "18. Inmaculada Concepción / 19. Juicio Final", en MORTE GARCíA, Carmen (comis.). Aragón y la pintura del Renacimiento. Zaragoza: Museo e Instituto "Camón Aznar", 1990, pp. 107-112.

MORTE GARCÍA, Carmen. "Tomás Peliguet y taller. Retablo de las Almas. Ca. 1550". En MORTE GARCíA, Carmen (comis.), El esplendor del Renacimiento en Aragón. Zaragoza: Gobierno de Aragón, Museo de Bellas Artes de Bilbao y Generalitat Valenciana, 2009, pp. 210-211.

PARAMO, Ludovico. De origine et processv Officii Sanctae Inqvisitionis eiusque diginitate \& vtilitate. Madrid: Ex Typologia Regia, 1598.

RODRÍGUEZ BARRAL, Paulino. "Los retablos de almas levantinos: hacia una redefinición visual de la geografía del más allá". Boletín de la Sociedad Castellonense de Cultura, LXXIX, 2003, pp. 603-648.

RODRÍGUEZ BARRAL, Paulino, La justicia del más allá. Iconografía en la Corona de Aragón en la Baja Edad Media. Valencia, P.U.V., 2007.

SELA DEL POZO COLL, Patricia. "Intercambio artístico y relaciones iconográficas: la Misa de San Gregorio". En COSMEN ALONSO, Concepción, HERRÁEZ ORTEGA, $\mathrm{M}^{\mathrm{a}}$ Victoria y PELLÓN GÓMEZ-CALCERRADA, María (coords.). El intercambio artístico entre los reinos hispanos y las cortes europeas en la Baja Edad Media. León: Universidad de León, 2009, pp. 191-201.

VILLACAMPA SANVICENTE, Susana. "El retablo de Montearagón en el Museo Diocesano de Huesca: estudio e informe tras su restauración (2001)". Aragonia Sacra, XV, Zaragoza, 2000, pp. 173-220.

VILLACAMPA SANVICENTE, Susana. "Manifestaciones artísticas de la fortaleza-abadía de Montearagón: los restos de un naufragio". Montearagón: un patrimonio por recuperar. Actas de los ciclos de conferencias celebrados en Huesca en abril de 2016 y febrero de 2017. Huesca: Instituto de Estudios Altoaragoneses, 2017, pp. 118-169. 